\title{
Cochrane
}

Library

Cochrane Database of Systematic Reviews

\section{Lumbar sympathectomy versus prostanoids for critical limb ischaemia due to non-reconstructable peripheral arterial disease} (Review)

Sen I, Agarwal S, Tharyan P, Forster R

Sen I, Agarwal S, Tharyan P, Forster R.

Lumbar sympathectomy versus prostanoids for critical limb ischaemia due to non-reconstructable peripheral arterial disease.

Cochrane Database of Systematic Reviews 2018, Issue 4. Art. No.: CD009366.

DOI: 10.1002/14651858.CD009366.pub2.

www.cochranelibrary.com 
TABLE OF CONTENTS

HEADER 1

ABSTRACT

PLAIN LANGUAGE SUMMARY

SUMMARY OF FINDINGS

BACKGROUND

OBJECTIVES

METHODS

RESULTS

Figure 1.

Figure 2.

Figure 3.

DISCUSSION

AUTHORS' CONCLUSIONS

ACKNOWLEDGEMENTS

REFERENCES

CHARACTERISTICS OF STUDIES

DATA AND ANALYSES

Analysis 1.1. Comparison 1 Prostanoids versus lumbar sympathectomy, Outcome 1 Complete ulcer healing without rest pain or major amputation at 24 weeks (per protocol analysis).

Analysis 1.2. Comparison 1 Prostanoids versus lumbar sympathectomy, Outcome 2 Complete ulcer healing without rest pain or major amputation at 24 weeks (ITT/sensitivity analysis).

Analysis 1.3. Comparison 1 Prostanoids versus lumbar sympathectomy, Outcome 3 Mortality (per protocol analysis).

Analysis 1.4. Comparison 1 Prostanoids versus lumbar sympathectomy, Outcome 4 Mortality (ITT/sensitivity analysis). APPENDICES

CONTRIBUTIONS OF AUTHORS

DECLARATIONS OF INTEREST

SOURCES OF SUPPORT

DIFFERENCES BETWEEN PROTOCOL AND REVIEW

INDEX TERMS 
[Intervention Review]

\section{Lumbar sympathectomy versus prostanoids for critical limb ischaemia due to non-reconstructable peripheral arterial disease}

Indrani Sen ${ }^{1}$, Sunil Agarwal2, Prathap Tharyan³, Rachel Forster ${ }^{4}$

1Vascular Surgery, Christian Medical College, Vellore, India. 2 Surgery Unit II, Christian Medical College, Vellore, India. ${ }^{3}$ Cochrane South Asia, Prof. BV Moses Center for Evidence-Informed Health Care and Health Policy, Christian Medical College, Vellore, India. ${ }^{4}$ Usher Institute of Population Health Sciences and Informatics, University of Edinburgh, Edinburgh, UK

Contact address: Indrani Sen, Vascular Surgery, Christian Medical College, Vellore, Tamil Nadu, 632004, India.dr.indranisen@gmail.com.

Editorial group: Cochrane Vascular Group.

Publication status and date: New, published in Issue 4, 2018.

Citation: Sen I, Agarwal S, Tharyan P, Forster R. Lumbar sympathectomy versus prostanoids for critical limb ischaemia due to non-reconstructable peripheral arterial disease. Cochrane Database of Systematic Reviews 2018, Issue 4. Art. No.: CD009366. DOI: 10.1002/14651858.CD009366.pub2.

Copyright @ 2018 The Cochrane Collaboration. Published by John Wiley \& Sons, Ltd.

\section{A B S T R A C T}

\section{Background}

Peripheral arterial disease (PAD) is a common circulatory problem that can lead to reduced blood flow to the limbs, which may result in critical limb ischaemia (CLI), a painful manifestation that occurs when a person is at rest. The mainstay of treatment for CLI is surgical or endovascular repair. However, when these means of treatment are not suitable, due to anatomical reasons or comorbidities, treatment for pain is limited. Lumbar sympathectomy and prostanoids have both been shown to reduce pain from CLI in people who suffer from non-reconstructable PAD, but there is currently insufficient evidence to determine if one treatment is superior. Due to the severity of the rest pain caused by $\mathrm{CLI}$, and its impact on quality of life, it is important that people are receiving the best pain relief treatment available, therefore interest in this area of research is high.

\section{Objectives}

To compare the efficacy of lumbar sympathectomy with prostanoid infusion in improving symptoms and function and avoiding amputation in people with critical limb ischaemia (CLI) due to non-reconstructable peripheral arterial disease (PAD).

\section{Search methods}

The Cochrane Vascular Information Specialist (CIS) searched the Specialised Register (last searched 29 March 2017) and CENTRAL (2017, Issue 2). The CIS also searched clinical trials databases for ongoing or unpublished studies.

\section{Selection criteria}

Randomised controlled trials (RCTs), with parallel treatment groups, that compared lumbar sympathectomy (surgical or chemical) with prostanoids (any type and dosage) in people with CLI due to non-reconstructable PAD.

\section{Data collection and analysis}

Three review authors independently selected trials, extracted data and assessed risk of bias. Any disagreements were resolved by discussion. We performed fixed-effect model meta-analyses, when there was no overt sign of heterogeneity, with risk ratios (RRs) and 95\% confidence intervals (Cls). We graded the quality of evidence according to GRADE.

\section{Main results}

We included a single study in this review comparing lumbar sympathectomy with prostanoids for the treatment of CLI in people with nonreconstructable PAD. The single study included 200 participants with Buerger's disease, a form of PAD, 100 in each treatment group, but 
only 162 were actually included in the analyses. The study compared an open surgical technique for lumbar sympathectomy with the prostanoid, iloprost, and followed participants for 24 weeks.

Risk of bias was low for most evaluated domains. Due to the nature of the treatment, blinding of the participants and those providing the treatment would be impossible as a surgical procedure was compared with intravenous injections. It was not mentioned if blinded assessors evaluated the study outcomes, therefore, we judged subjective outcomes (i.e. pain reduction) to be at unclear risk of detection bias and objective outcomes (i.e. ulcer healing, amputation and mortality) at low risk of detection bias. We also rated the risk of attrition bias as unclear; 38 out of 200 (19\%) participants were not included in the analysis without clear explanation (16 of 100 in the iloprost arm and 22 of 100 in the sympathectomy arm). The quality of evidence was low due to serious imprecision because the study numbers were low and there was only one study included.

The single included study reported on the outcome of complete healing without pain or major amputation, which fell under three separate outcomes for our review: relief of rest pain, complete ulcer healing and avoidance of major amputation. We chose to keep the outcome as a singularly reported outcome in order to not introduce bias into the outcomes, which may have been the case if reported separately. The limited evidence suggests participants who received prostaglandins had improved complete ulcer healing without rest pain or major amputation when compared with those who received lumbar sympathectomy (RR 1.63,95\% $\mathrm{Cl} 1.30$ to 2.05 ), but as it was the only included study, we rated the data as low-quality and could not draw any overall conclusions. The study authors stated that more participants who received prostaglandins reported adverse effects, such as headache, flushing, nausea and abdominal discomfort, but only one participant experienced severe enough adverse effects to drop out. Five participants who underwent lumbar sympathectomy reported minor wound infection (low-quality evidence). There was no reported mortality in either of the treatment groups (low-quality evidence).

The included study did not report on claudication distances, quality of life or functional status, ankle brachial pressure index (ABPI), tissue oxygenation or toe pressures, or progression to minor amputation, complications or provide any cost-effectiveness data.

\section{Authors' conclusions}

Low-quality evidence from a single study in a select group of participants (people with Buerger's disease) suggests that prostaglandins are superior to open surgical lumbar sympathectomy for complete ulcer healing without rest pain or major amputation, but possibly incur more adverse effects. Further studies are needed to better understand if prostaglandins truly are more efficacious than open surgical lumbar sympathectomy and if there are any concerns with adverse effects. It would be of great importance for future studies to include other forms of PAD (as Buerger's disease is a select type of PAD), other methods of sympathectomy as well as data on quality of life, complications and cost-effectiveness.

\section{PLAIN LANGUAGE SUMMARY}

\section{Lumbar sympathectomy versus prostanoids for critical limb ischaemia due to non-reconstructable peripheral arterial disease}

\section{Background}

People with peripheral arterial disease (PAD) have narrowed arteries which means it can be difficult to get sufficient blood to the extremities of the body, especially the legs. This lack of blood flow (ischaemia) over a long period can become painful. The pain usually becomes apparent only when a person has been walking a certain distance (intermittent claudication), but as the disease progresses the lack of blood flow worsens and the person may experience extreme pain while at rest (critical limb ischaemia (CLI)). Generally, if a person's blood vessels are in good enough health and the person does not suffer other illnesses that could complicate general anaesthesia, surgical repair of the arteries is considered and could help reduce ischaemic pain. However, in some people such a repair is not advised or possible, and their pain relief options are limited. Lumbar sympathectomy, which can be carried out by surgical procedure or by injection of a chemical agent, and the use of intravenous prostaglandins (lipids which aid in recovery at sites of tissue damage or infection that are injected into the vein via a syringe or catheter), can help improve blood flow and reduce pain. Both have been shown to help reduce rest pain in people who cannot have surgical repair. It is unclear at this time which of these techniques is superior for pain reduction, ulcer healing, reduction in amputation or other outcomes important to people with CLI.

\section{Study characteristics and key results}

For this review we only identified one study that met the inclusion criteria (current until 29 March 2017). This study randomised 200 participants (162 included in analysis) and compared surgical lumbar sympathectomy with the prostaglandin, iloprost, in people with Buerger's disease, a form of PAD, and followed participants for 24 weeks. This study found evidence of increased complete ulcer healing without rest pain or major amputation in the participants who received intravenous prostaglandin compared with those that received surgical lumbar sympathectomy. However, those who received prostaglandins were more likely to report adverse events such as headache, flushing, nausea and abdominal discomfort. There were no reported deaths in either treatment group. The single included study did not report on other planned outcomes for this review such as walking distances and quality of life or functional status. The single study was limited to the specific form of PAD known as Buerger's disease, and to surgical lumbar sympathectomy, making it difficult to generalise the findings to all types of PAD and all methods of lumbar sympathectomy.

\section{Quality of evidence}


Overall, the study had little risk of bias due to design. Blinding of the participants and those that administered the treatment would be impossible, but there was no mention of blinding of the people who evaluated the outcomes, which would have been a possibility. Due to this, we rated the outcomes that had subjective measures (measures that can be influenced by or based on personal beliefs or feelings), such as relief of rest pain as unclear risk of bias, but the outcomes that had objective measures (measures that are not influenced by or based on personal beliefs or feelings) such as ulcer healing, amputation and mortality as low risk of bias. Also, there was a large number of participants not included in the analysis (38 of the $200,19 \%$ ), in both groups, with inadequate reasons as to why, so we rated bias due to incomplete outcome data as unclear. The quality of the evidence, therefore, was low for the outcomes evaluated as the number of participants included was low and only a single study reported evidence. 


\begin{tabular}{|c|c|c|c|c|c|c|c|}
\hline \multirow{11}{*}{ 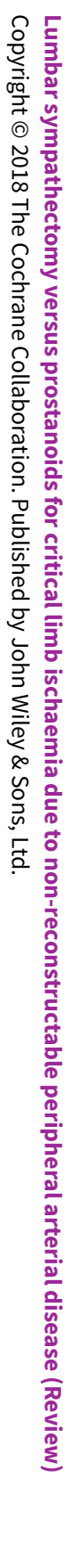 } & \multicolumn{7}{|c|}{$\begin{array}{l}\text { S U M M A R Y O F F I N D I N G S } \\
\text { Summary of findings for the main comparison. } \\
\text { peripheral arterial disease }\end{array}$} \\
\hline & \multicolumn{7}{|c|}{ Prostanoids versus lumbar sympathectomy for critical limb ischaemia due to non-reconstructable peripheral arterial disease } \\
\hline & \multicolumn{7}{|c|}{$\begin{array}{l}\text { Participants or population: people with critical limb ischaemia due to non-reconstructable peripheral arterial disease } \\
\text { Settings: } 12 \text { centres in Turkey } \\
\text { Intervention: prostanoids versus lumbar sympathectomy }\end{array}$} \\
\hline & \multirow[t]{3}{*}{ Outcomes } & \multicolumn{2}{|c|}{$\begin{array}{l}\text { Illustrative comparative risks } \\
(95 \% \mathrm{Cl})\end{array}$} & \multirow[t]{3}{*}{$\begin{array}{l}\text { Relative effect } \\
(95 \% \mathrm{CI})\end{array}$} & \multirow{3}{*}{$\begin{array}{l}\text { Number of par- } \\
\text { ticipants } \\
\text { (studies) }\end{array}$} & \multirow{3}{*}{$\begin{array}{l}\text { Quality of the } \\
\text { evidence } \\
\text { (GRADE) }\end{array}$} & \multirow[t]{3}{*}{ Comments } \\
\hline & & Assumed risk & $\begin{array}{l}\text { Corresponding } \\
\text { risk }\end{array}$ & & & & \\
\hline & & $\begin{array}{l}\text { Lumbar sym- } \\
\text { pathectomy }\end{array}$ & Prostanoids & & & & \\
\hline & $\begin{array}{l}\text { Complete ulcer heal- } \\
\text { ing without rest pain } \\
\text { or major amputation } \\
\text { (per protocol) } \\
\text { Clinical assessment } \\
\text { follow-up: } 24 \text { weeks }\end{array}$ & 526 per 1000 & $\begin{array}{l}331 \text { per } 1000 \\
\text { (158 to } 552)\end{array}$ & $\begin{array}{l}\text { RR } 1.63 \\
(1.30 \text { to } 2.05)\end{array}$ & $\begin{array}{l}162 \\
\text { (1 study) }\end{array}$ & $\begin{array}{l}\oplus \oplus \ominus \ominus \\
\text { low } 1\end{array}$ & $\begin{array}{l}\text { The outcomes 'relief of rest pain', 'complete ul- } \\
\text { cer healing' and 'avoidance of amputation' were } \\
\text { all derived from a single outcome reported by } \\
\text { Bozkurt } 2006 \text { as "complete healing without pain } \\
\text { or major amputation". We chose to deviate from } \\
\text { the review protocol and combine the outcomes, } \\
\text { reflecting the single included study in order to } \\
\text { limit potential bias. }\end{array}$ \\
\hline & $\begin{array}{l}\text { Intermittent and ab- } \\
\text { solute claudication } \\
\text { distances }\end{array}$ & See comment & See comment & Not estimable & & & Not reported in included study. \\
\hline & $\begin{array}{l}\text { Quality of life and } \\
\text { functional status }\end{array}$ & See comment & See comment & Not estimable & & & Not reported in included study. \\
\hline & $\begin{array}{l}\text { Adverse effects } \\
\text { Clinical assessment } \\
\text { follow-up: } 24 \text { weeks }\end{array}$ & See comment & See comment & Not estimable & $\begin{array}{l}162 \\
\text { (1 study) }\end{array}$ & $\begin{array}{l}\oplus \oplus \ominus \ominus \\
l o w^{1}\end{array}$ & $\begin{array}{l}\text { Adverse effects were not reported in a way that } \\
\text { we could include in an analysis. Authors of the } \\
\text { one included study reported more adverse ef- } \\
\text { fects in participants that received prostaglandin, } \\
\text { but only one participant withdrew due to ad- } \\
\text { verse effects. }\end{array}$ \\
\hline & Mortality & See comment & See comment & Not estimable & 162 & $\oplus \oplus \ominus \ominus$ & No mortality reported in this trial. \\
\hline
\end{tabular}


*The basis for the assumed risk (e.g. the median control group risk across studies) is that the risk in the control group. The corresponding risk (and its $95 \%$ confidence interval) is based on the assumed risk in the comparison group and the relative effect of the intervention (and its 95\% $\mathrm{Cl}$ ).

Cl: confidence interval; RR: risk ratio.

\section{GRADE Working Group grades of evidence}

High-quality: Further research is very unlikely to change our confidence in the estimate of effect.

Moderate-quality: Further research is likely to have an important impact on our confidence in the estimate of effect and may change the estimate.

Low-quality: Further research is very likely to have an important impact on our confidence in the estimate of effect and is likely to change the estimate.

Very low-quality: We are very uncertain about the estimate.

${ }^{1}$ Downgraded by two levels due to serious imprecision: study sample size was small with significant dropouts, and the data were only from a single trial. 


\section{B A C K G R O U N D}

\section{Description of the condition}

Lower limb peripheral arterial disease (PAD) refers to the obstruction or narrowing of the large arteries of the lower limbs, most commonly caused by atheromatous plaque or a thrombus (blood clot). The most common cause of PAD is atherosclerosis, which affects more than 200 million people worldwide (Kullo 2016). Risk factors for PAD include smoking, diabetes, hypertension and high cholesterol (Faglia 2009; Fowkes 2013). People who suffer from PAD have a greatly increased risk of suffering from cardiovascular problems, including myocardial infarction, stroke and death from cardiovascular disease (Steg 2007).

It has been estimated that PAD is prevalent in about $3 \%$ to $10 \%$ of the population (Norgren 2007). People with PAD often present with muscle pain (intermittent claudication) in the leg from mild exertion, such as walking, or decreased blood flow to the legs that can be painful at rest (critical limb ischaemia (CLI)). In a study from 2001 that included participants with PAD, 32\% of participants presented with intermittent claudication during exertion (McDermott 2001). Intermittent claudication is often an early symptom of PAD and has a low long-term amputation rate. $\mathrm{CLI}$ is characterised by severe pain at rest or tissue loss (ulceration or gangrene), or both. For people with PAD, the 10-year risk of developing $\mathrm{CLI}$ is $30 \%$ (Aquino 2001).

Diagnosis of PAD is commonly achieved by measuring the ankle brachial index $(A B I)$ which is a measure of the systolic blood pressure of the posterior tibial and dorsalis pedis arteries (arteries near ankle and the big toe, respectively), normalised to the brachial pressure (NICE 2012; Norgren 2007). A lower ABI indicates PAD, with the cut-off being 0.90 (Hirsh 2001). The Fontaine Classification system is commonly used to grade the severity of PAD and ranges from stage I, which indicates the person is asymptomatic, to stage IV, indicating the presence of ulceration and gangrene (Fontaine 1954).

NICE guidelines recommend treatment of intermittent claudication with exercise in the first instance, after which treatment with pharmacotherapy, specifically the vasodilator naftidrofuryl oxalate, is recommended if exercise alone does not alleviate symptoms (NICE 2012). Endovascular procedures, such as angioplasty and stenting, as well as bypass surgery are only considered if other forms of treatment do not relieve symptoms of intermittent claudication (NICE 2012; Norgren 2007). Angioplasty or bypass are recommended treatment strategies for people with $\mathrm{CLI}$, as well as pain management with paracetamol or opioids (NICE 2012; Norgren 2007). Amputation is only considered for PAD if all other treatment options are exhausted or found to not be suitable.

Treatment of PAD with amputation of the affected limb has been decreasing, which has coincided with an increase in surgical and endovascular procedures to improve blood flow (Rowe 2009). However, many people have non-reconstructable disease with very poor distal blood flow and often undergo major amputation for the relief of rest pain. Amputation rates for pain relief in these people are high, up to $45 \%$, because the treatment options are very limited (Dormandy 1999). Lumbar sympathectomy and prostanoid infusion are alternative treatment options for people with PAD who are not suitable for endovascular or surgical repair (Diehm 2004; Lee 2006; Pieri 2005).

\section{Description of the intervention}

Lumbar sympathectomy is a procedure that disrupts the sympathetic chain in the lumbar region of the spinal cord, which is generally performed to increase blood flow, reduce pain, or both (Karanth 2016; Pieri 2005). This procedure can be performed using a radiologically-guided chemical injection or by a surgical procedure. Radiographically-guided chemical lumbar sympathectomy is carried out by injection of a chemical agent into the lumbar sympathetic ganglia under computer tomography (CT) guidance, usually at the L3 level to achieve neurolysis of the lumbar sympathetic chain. Surgery involves surgical division of the sympathetic chain, which can be done via open surgery or laparoscopically. In the past, blind sympathectomy was also done but this has now been largely abandoned due to the availability of CT (Tay 2002).

Prostanoids are a group of lipid compounds that, when given intravenously, act as a vasodilator and reduce blood platelet aggregation (Robertson 2013). The evidence is mixed regarding the effect of prostanoids as a method of pain relief for PAD, as well as the ability of the treatment to improve ulcer healing, increase limb salvage and improve mortality, with some studies claiming they do improve symptoms and others claiming there is no effect (Abu Dabrh 2015; Robertson 2013; Ruffolo 2010).

\section{How the intervention might work}

Lumbar sympathectomy works by disruption of the efferent autonomic pain pathways and reduction of vasoconstriction caused by sympathetic nerves. The resulting vasoconstriction leads to distal reperfusion and pain relief (Tay 2002).

Prostanoids are thought to act by causing an alteration in tissue perfusion by changing small artery compliance and helping to increase blood flow to ischaemic limbs as well as helping to protect the endothelium. Prostanoids act as a vasodilatory and antithrombotic agent. Common prostanoids include prostaglandin E1 (PGE1) and the prostacyclin derivative, iloprost (Norgren 2007).

\section{Why it is important to do this review}

People with symptomatic PAD often present with claudication and rest pain. While some people can achieve pain relief through angioplasty or bypass procedures, many are not suitable for such procedures and pain needs to be managed in alternative ways. Pain relief and ulcer healing in this group of people are traditionally managed by sympathectomy, but the amputation rates for pain relief in these people are high (up to 45\%). Recent trials on prostanoid use have shown positive outcomes for pain relief and ulcer healing in this group of people, but results are inconsistent. A systematic review of well conducted and reported randomised controlled trials (RCTs) is required to evaluate the comparative efficacy of sympathectomy versus prostanoid use. If pain relief, limb salvage and functional outcomes with prostanoid use are comparable to sympathectomy, people may be able to avoid either a radiological procedure or surgery that is necessary with lumbar sympathectomy.

\section{O B J E C T IVES}

To compare the efficacy of lumbar sympathectomy with prostanoid infusion in improving symptoms and function and avoiding 
amputation in people with critical limb ischaemia (CLI) due to nonreconstructable peripheral arterial disease (PAD).

\section{METHODS}

\section{Criteria for considering studies for this review}

\section{Types of studies}

We included one parallel-group randomised controlled trial (RCT) of lumbar sympathectomy versus prostanoids.

\section{Types of participants}

We included participants with CLI due to non-reconstructable PAD.

We define $\mathrm{CLI}$ as rest pain for more than two weeks, requiring analgesics, or tissue loss (ulceration or gangrene), or the participant meets at least one of the following diagnostic criteria in the affected limb.

1. Ankle artery occlusion absolute pressure $<50 \mathrm{mmHg}$ or ankle brachial pressure index $(\mathrm{ABPI})<0.4$.

2. Toe pressure $<40 \mathrm{mmHg}$.

3. Transcutaneous oxygen measurement $\left(\mathrm{TcPO}_{2}\right)<20 \mathrm{mmHg}$ when lying down breathing room air, if available.

We define 'non-reconstructable' as the following: there is no reasonable open surgical or endovascular revascularisation option, as determined by the treating vascular specialist. Factors that may contribute to the determination of inoperability include the following.

1. Anatomical considerations

a. no outflow targets

b. no appropriate conduit (i.e. vein for bypass)

c. long segment occlusions or calcified lesions that predict poor outcome with endovascular approaches

2. High risk medical conditions
a. unstable cardiac disease
b. renal insufficiency
c. uncontrolled diabetes

3. History of prior failed revascularisation attempts

4. Primary assessment of vascular operability was performed by the vascular surgeon. If anatomical considerations were invoked, a second physician may be consulted. The second physician could be a vascular surgeon, interventional radiologist, cardiologist, or vascular medicine specialist.

\section{Types of interventions}

We planned to include studies that compared lumbar sympathectomy with prostanoids for PAD. Lumbar sympathectomy could be undertaken chemically or surgically (open or blind), as well as unilateral or bilateral. We included any dosage and type of prostanoids, including, but not limited to, prostaglandin E1 (PGE1) and prostacyclin (PGI).

\section{Types of outcome measures}

\section{Primary outcomes}

1. Relief of rest pain

2. Ulcer healing

\section{Avoidance of major amputation}

\section{Secondary outcomes}

1. Intermittent and absolute claudication distance (pain-free walking distance and maximum walking distance, respectively)

2. ABPI, tissue oxygenation $\left(\mathrm{TCPO}_{2}\right)$ and toe pressure

3. Progression to minor amputation

4. Quality of life and functional status

5. Adverse effects

6. Complications

7. Mortality

8. Analysis of cost-effectiveness (if data are available)

Outcomes are classified as short-term (within six months), medium-term (over six months to two years), and long-term (more than two years).

\section{Search methods for identification of studies}

We applied no language restriction on publications.

\section{Electronic searches}

The Cochrane Vascular Information Specialist (CIS) searched the following databases for relevant trials.

1. The Cochrane Vascular Specialised Register (29 March 2017).

2. The Cochrane Central Register of Controlled Trials (CENTRAL; 2017, Issue 2) via The Cochrane Register of Studies Online.

See Appendix 1 for details of the search strategy used to search CENTRAL.

The Cochrane Vascular Specialised Register is maintained by the $\mathrm{CIS}$ and is constructed from weekly electronic searches of MEDLINE Ovid, Embase Ovid, CINAHL, AMED, and through handsearching relevant journals. The full list of the databases, journals and conference proceedings which have been searched, as well as the search strategies used are described in the Specialised Register section of the Cochrane Vascular module in the Cochrane Library (www.cochranelibrary.com).

The CIS also searched the following trials registries for details of ongoing and unpublished studies (29 March 2017).

1. CinicalTrials.gov (www.clinicaltrials.gov).

2. World Health Organization International Clinical Trials Registry Platform (www.who.int/trialsearch).

3. ISRCTN Register (www.isrctn.com).

See Appendix 2 for details of these searches.

\section{Searching other resources}

We scrutinised bibliographies of relevant publications found from the electronic searches to identify any further randomised trials. We contacted authors of trials for further information in cases where there were missing data or doubts about whether to include the trials in the review. We contacted authors of identified potentially relevant published RCTs in order to get further information about published or unpublished studies. 


\section{Data collection and analysis}

We used the software used for preparing and maintaining Cochrane Reviews to compile data and generate meta-analysis (Review Manager 2014).

\section{Selection of studies}

Three review authors (IS, SA and PT) independently selected trials for inclusion. In the event of disagreements, we reached consensus by referral to the original report, contacting authors of trials, and through discussion. We recorded the selection process in sufficient detail to complete a PRISMA flow diagram (Liberati 2009).

\section{Data extraction and management}

Three review authors (IS, SA and PT) independently extracted data using a standardised form. We extracted data that included information regarding the trial design, participant characteristics (for example, diabetes, hypertension, systemic disease, past interventions, drug history, functional status and other demographic data), therapy type, dosages, treatment periods/duration, and for sympathectomy, the spinal level it was performed at. We collected information on relief of rest pain, ulcer healing, pain-free walking, maximum walking distances and any other available outcomes. We also collected information on adverse effects from each trial. Where necessary, we sought information from the principal authors of the included studies. The three review authors that performed data extraction cross-checked the extracted data for verification.

\section{Assessment of risk of bias in included studies}

Three review authors (IS, SA and PT) independently evaluated the risk of bias in the one included trial on the following six components: selection bias (sequence generation and allocation concealment), performance and detection bias (blinding), attrition bias (incomplete outcome data), reporting bias (selective outcome reporting), and other biases. For each of these components, we assigned a judgement regarding the risk of bias as high, low or unclear (Higgins 2011). As blinding of participants and investigators is not achievable due to the nature of the treatments, we did not specifically assess performance bias. For detection bias, we made judgements separately for objectively and subjectively ascertained measures. We recorded these assessments for the included study in the standard 'Risk of bias' tables. We used these assessments in making judgements on overall study quality while preparing a 'Summary of findings' table. We attempted to contact the trial authors for clarification when methodological details were unclear. We resolved differences by discussion.

\section{Measures of treatment effect}

We synthesised dichotomous data with the Mantel-Haenszel method to derive pooled, weighted RRs. We planned to combine continuous data summarised by arithmetic means and SDs using the inverse variance method to derive the weighted mean difference (WMD). If the same continuous outcomes in studies were measured using different scales, we planned to use the inverse variance method to derive standardised mean differences (SMDs) and express the pooled results as odds ratios (ORs) and as absolute measures using methods described in Deeks 2011.

\section{Unit of analysis issues}

We only included one simple parallel-group design study. The individual participant is the unit of analysis.

\section{Dealing with missing data}

We attempted to obtain missing data from trial authors. Where possible, we extracted data to allow an intention-to-treat (ITT) analysis in which all randomised participants are analysed in the groups to which they were originally randomised. If there was a discrepancy in the numbers randomised and the numbers analysed in each treatment group, we calculated the percentage lost to follow-up in each group and reported this information. If dropouts exceed $10 \%$, we assigned the worst outcome to those lost to followup for dichotomous outcomes and assessed the impact of this in sensitivity analyses with the results of completers.

For continuous data that were missing standard deviations (SDs), we planned to either calculate these from other available data such as standard errors, or impute them using methods suggested in Deeks 2011. We did not intend to make any assumptions about loss to follow-up for continuous data and planned to analyse results for those who completed the trial.

\section{Assessment of heterogeneity}

We planned to assess heterogeneity between the trials by visual examination of the forest plot to check for consistency in the direction of effect estimates and for overlapping $\mathrm{Cls}$. We planned to use the $\mathrm{Chi}^{2}$ test for homogeneity at a $10 \%$ level of significance to detect statistical heterogeneity. We planned to use the $\mathrm{I}^{2}$ statistic to assess inconsistency (the percentage of the variability in effect estimates that is due to heterogeneity rather than sampling error) (Higgins 2002). We intended to interpret a value of 12 of $50 \%$ or greater to denote significant heterogeneity and utilise a randomeffects model. If severe heterogeneity was present $\left(1^{2}>=75 \%\right)$ and could not be explained by differences across the trials in terms of clinical or methodological features or by subgroup analyses (see below), we intended to not combine the trials in a meta-analysis but present the results in a forest plot.

\section{Assessment of reporting biases}

We assessed the included study for adequacy of reporting of data for prestated outcomes and for selective reporting of outcomes. We noted judgements based on the risk of selective reporting in the 'Risk of bias' table in the Characteristics of included studies table. We reported risk of selective outcome reporting in the results under Risk of bias in included studies. We planned to assess the likelihood of potential publication bias using funnel plots (Egger 1997), provided that there were at least 10 trials assessing particular outcomes in a meta-analysis.

\section{Data synthesis}

We utilised a fixed-effect model to generate risk ratios (RRs) and 95\% confidence intervals (Cls) of homogeneous dichotomous data for each outcome with sufficient data. We planned to combine continuous variables to mean difference with $95 \% \mathrm{Cls}$.

\section{Subgroup analysis and investigation of heterogeneity}

If data permitted, we planned to carry out subgroup analyses using the following subgroups: age, sex, diabetes, cardiac comorbidity, 
and disease type (thromboangitis obliterans (TAO or Buerger's disease), atherosclerosis, vasculitis), as well as duration of followup (short-, medium-, and long-term).

\section{Sensitivity analysis}

We intended to undertake sensitivity analyses if trials reported dropout rates of $10 \%$ or greater, to ascertain differences in outcomes of ITT analysis (all dropouts were assigned to the worst outcome for dichotomous outcomes) and analysis of completers as described in Dealing with missing data. However, due to the high number of dropouts in the single included study, we chose to report a per protocol analysis (only reporting those who actually had follow-up information) as our main analyses and then use an ITT analysis for the sensitivity analysis, with the dropouts assigned the worst outcome. We felt this best demonstrated the actual data collected, without making assumptions about the large number of dropouts.

We planned to calculate the results using all studies and then evaluate the exclusion of studies judged to be at high risk of bias for the primary outcomes across the domains evaluated. We also planned to assess the estimates of effect with and without missing data imputation, if such data were included.

\section{Summarising and interpreting results: 'summary of findings' table}

We used the GRADE approach to interpreting findings (Schünemann 2011), and used the online GRADEpro GDT software to create a 'Summary of findings' table with information concerning the quality of evidence, the magnitude of effect of the interventions examined, and the sum of available data on the following seven critically important outcomes (GRADEpro GDT 2015): relief of rest pain, complete ulcer healing, avoidance of amputation, intermittent and absolute claudication distances, quality of life and functional status, adverse effects, and mortality, from each included study in the comparison.

\section{RESULTS}

\section{Description of studies}

See: Characteristics of included studies; Characteristics of excluded studies

\section{Results of the search}

We retrieved three reports from the performed searches. We obtained the full text for these reports to assess their eligibility. After we excluded irrelevant reports, we identified only a single study (two reports) for inclusion. The full study selection flow diagram can be found in Figure 1. 
Figure 1. Study flow diagram.

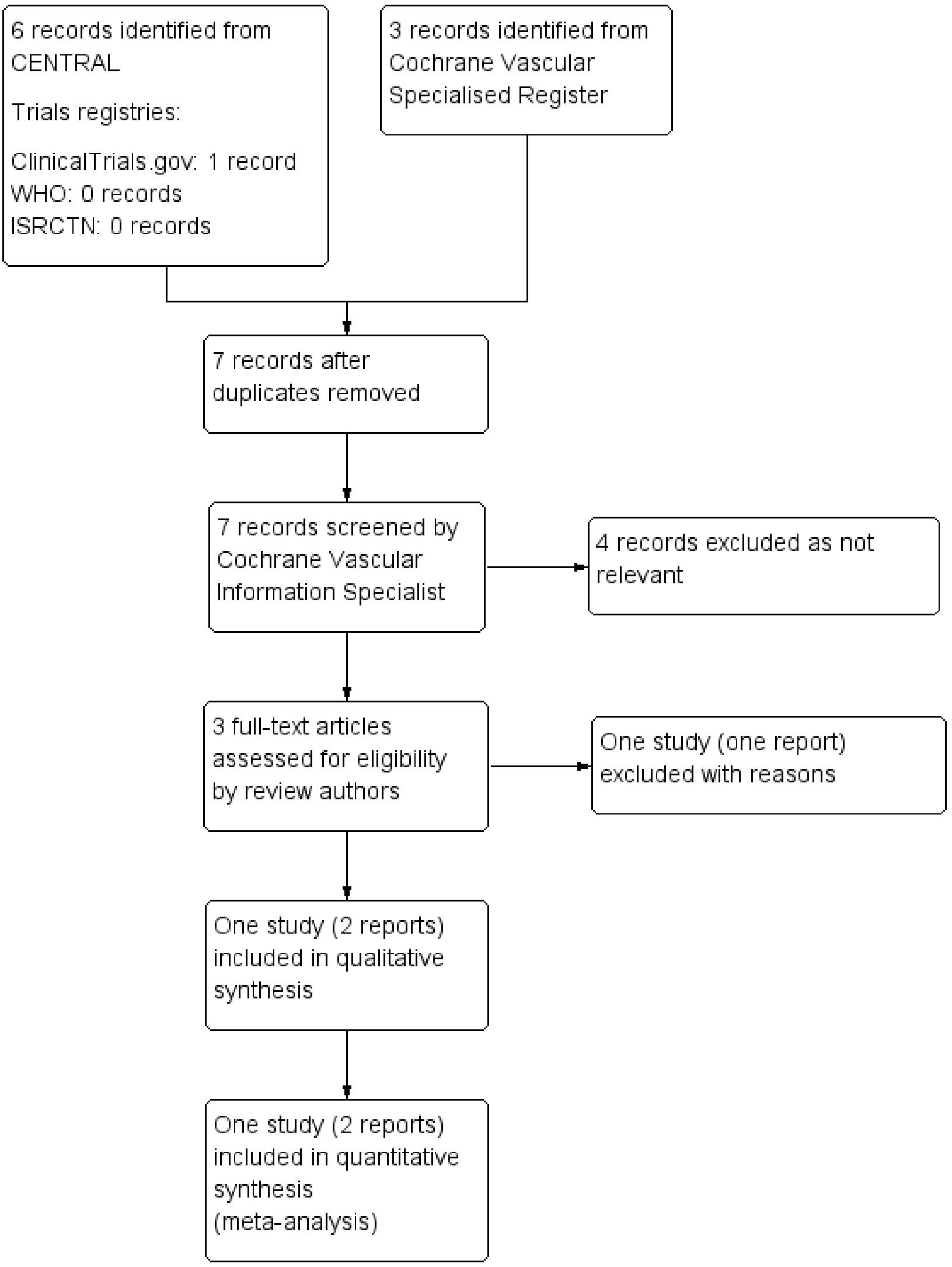




\section{Included studies}

Bozkurt 2006 was the only study that met the inclusion criteria and is described more thoroughly in the Characteristics of included studies table. This study was a randomised parallel-group, multicentre controlled clinical trial. A total of 200 participants diagnosed with a form of arterial disease, called Buerger's disease, were randomised in the study, 162 were analysed. This study compared the prostaglandin, iloprost, with lumbar sympathectomy by open surgery. Outcome measures analysed were complete ulcer healing, relief of ischaemic rest pain, avoidance of major amputation, complications, adverse effects and mortality. The trial assessed outcomes at four weeks and 24 weeks; for our analysis we used data at 24 weeks.

\section{Excluded studies}

We excluded the Petronella 2004 study from our review. Further information can be found in the Characteristics of excluded studies table. This study did not match our inclusion criteria as it included some participants requiring surgical revascularisation. This is likely to influence the outcome of the intervention under study.
Surgical revascularisation is the first line of management for critical limb ischaemia (CLI), without which relief of ischaemic pain is low and rates of limb loss are high. Treating such a participant group with prostaglandin or sympathectomy may cause a delay in revascularisation and theoretically worsen the stage of ischaemia. Performance of revascularisation after the trial intervention also influences the outcome follow-up: participants with successful revascularisation will report better outcomes. It would then be unclear if this improvement is because of the study intervention or the revascularisation. The authors state that "the patients were randomly allocated...though they were well matched in terms of disease status". There was no sample size calculation and the method of randomisation, allocation concealment and other methods was unclear. The study also included a few participants with early stages of disease, again, prostaglandin or sympathectomy are not acceptable treatment modalities in such participants.

\section{Risk of bias in included studies}

The assessments regarding the risk of bias are depicted in Figure 2 and Figure 3.

\section{Figure 2. Risk of bias graph: review authors' judgements about each risk of bias item presented as percentages} across all included studies.

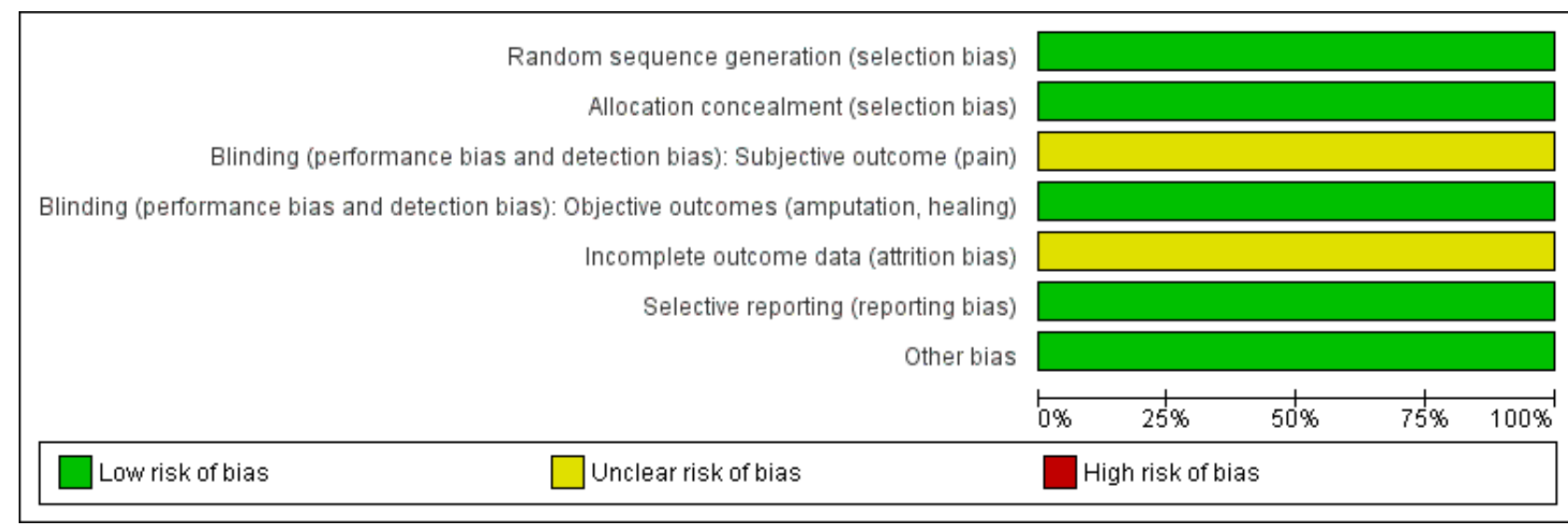


Figure 3. Risk of bias summary: review authors' judgements about each risk of bias item for each included study.

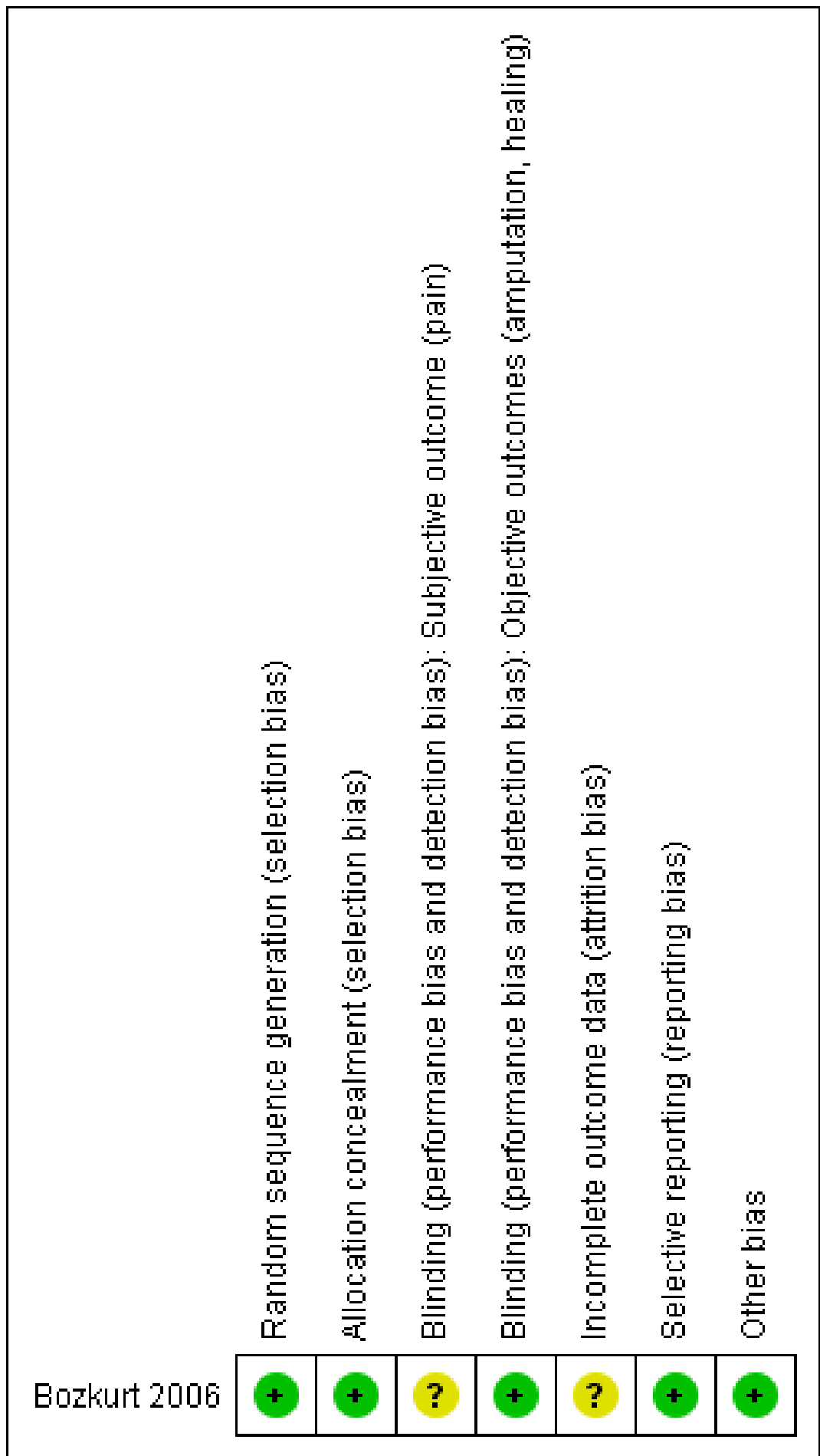

\section{Allocation}

A computer-generated random sequence produced by an independent statistician was utilised for randomisation so we judged the Bozkurt 2006 trial to be free of the risk of selection bias for sequence generation and allocation concealment.

\section{Blinding}

Due to the nature of the interventions, injection of prostaglandin versus open surgical lumbar sympathectomy, blinding of the participants and investigators (performance bias) could not be sufficiently carried out. We assessed the risk of detection bias in the included trial separately with regard to subjective and objective outcomes. 
We considered subjective outcomes (pain) to have an unclear risk of bias. The study authors report the change in the clinical severity as indirect evidence of improvement in pain, but there was no objective pain measure score reported in the trial. It was not indicated by the study authors if a blind assessor was utilised to collect outcome data.

We judged objective outcomes (amputation, ulcer healing) to have a low risk of bias. Ulcer healing was assessed by objective measurement of ulcer size and backed-up with follow-up data. Amputation is a definitive clinical endpoint, so the risk of detection bias for the objective outcomes was low.

\section{Incomplete outcome data}

Of the 200 participants randomised, only 162 were included in the analysis and the study authors stated that there were "insufficient data for the remaining patients". In both groups there were participants not included ( $\mathrm{n}=16$ in the iloprost arm, $n=22$ in the sympathectomy arm), but no reasons were given for why the participant data were not available. We judged the attrition bias to be unclear and because this was the only included study, we reported the outcomes as a per protocol analysis and a separate intention-to-treat (ITT) analysis with all dropouts assumed to have the worst outcome.

\section{Selective reporting}

Although the trial was not registered, all proposed outcome measures were reported. We judged the risk of reporting bias to be low.

\section{Other potential sources of bias}

We could not identify any other potential source of bias in this trial.

\section{Effects of interventions}

See: Summary of findings for the main comparison Prostanoids versus lumbar sympathectomy for critical limb ischaemia due to non-reconstructable peripheral arterial disease

All outcomes reported are from a single trial (Bozkurt 2006). The trial did not report data on intermittent or absolute claudication distance, ankle brachial pressure index (ABPI), tissue oxygenation $\left(\mathrm{TCPO}_{2}\right)$, toe pressure, progression to minor amputation, quality of life/functional status or analysis of cost-effectiveness. The main outcome in the Bozkurt 2006 trial was "complete healing without pain or major amputation" which we believe fits the criteria for our outcomes of 'complete ulcer healing', 'avoidance of amputation' and 'pain relief'. As this was the only included study, we chose to report the findings as they were presented in the study, as a single outcome, in order to reduce the risk of bias when presenting the results.

Also, we intended to report the outcomes in an ITT analysis, but due to the large number of dropouts we decided to present the primary analysis on a per protocol basis. We also included a secondary ITT analysis with dropouts assumed to have the worst outcome. We believe this addresses the discrepancy in participant numbers in a clear manner.

\section{Complete ulcer healing without rest pain or major amputation}

For the single reporting study, there were 72 participants in the prostaglandin arm and 41 in the sympathectomy arm who reported pain relief 24 weeks after treatment. These findings provide lowquality evidence in favour of prostaglandin as an intervention when compared with lumbar sympathectomy (risk ratio (RR) 1.63, 95\% confidence interval (CI) 1.30 to 2.05; Analysis 1.1). The evidence for this outcome comes from only a single study so we graded the quality as low due to serious imprecision.

\section{Adverse effects}

Insufficient data were provided in the single reporting study to include adverse effects in a meta-analysis. However, the authors of the study noted that more participants receiving the prostaglandin reported side effects which included headache, flushing, nausea and abdominal discomfort, but only one person in this group had to drop out due to symptoms. Five participants undergoing lumbar sympathectomy had minor wound infection.

\section{Mortality}

The Bozkurt 2006 trial reported no mortality in either group so we could not calculate an overall RR at this time (Analysis 1.3). We graded the evidence as low due to serious imprecision.

\section{Sensitivity analysis}

In the single included trial there is a large number of missing participant data in both arms, with a total rate of $19 \%$. Our primary analysis was based on a per protocol analysis: only those that received treatment and had follow-up data reported. For sensitivity analysis we performed an ITT analysis, which included all participants randomised and outcomes for those that were lost to follow-up to be imputed as the worst possible. For the outcome 'complete ulcer healing without rest pain or major amputation' that means no further participants were added as events and for 'morality', all missing participants were assumed to have died.

For sensitivity analysis for 'complete ulcer healing without rest pain or major amputation' when all participants randomised were included the strength of the point estimate and $95 \% \mathrm{Cl}$ increased, but the overall finds were unchanged (RR $1.76,95 \% \mathrm{Cl} 1.35$ to 2.29; Analysis 1.2).

Sensitivity analysis of mortality showed no evidence of a difference between the treatments (RR $0.73,95 \% \mathrm{Cl} 0.41$ to 1.30 ; Analysis 1.4).

\section{Subgroup analysis}

We could not perform subgroup analyses as results were only from a single trial that did not include subgroup level data.

\section{DISCUSSION}

\section{Summary of main results}

The results of a single trial favour the use of prostaglandins for complete ulcer healing without rest pain or major amputation in people presenting with critical limb ischaemia (CLI) and diagnosed to have non-reconstructable peripheral arterial disease (PAD) compared with open surgical lumbar sympathectomy; we judged this evidence to be of low-quality. The study reported a possible increase in mild adverse events in the group that was assigned prostaglandins, and there were no reported deaths for either treatment group; we also judged the evidence of these outcomes to be of low-quality. No data were provided on claudication distances, ankle brachial pressure index (ABPI), tissue oxygenation $\left(\mathrm{TCPO}_{2}\right)$ 
and toe pressures, progression to minor amputation, quality of life and functional status, complications, analysis of cost-effectiveness, or long-term outcomes.

\section{Overall completeness and applicability of evidence}

This review provides low-quality evidence on the benefit of use of prostaglandins in the management of people presenting with non-reconstructable CLI. Only one study presented data sufficient to adequately address the objectives of this review. There were a high number of participants lost to follow-up without explanation, reducing the completeness of the reporting. The study only included participants with Buerger's disease, so this review provides evidence supporting the role of prostaglandins in the treatment of this participant group only. These results are significant as, unlike atherosclerotic disease which has better revascularisation options, Buerger's disease presents with higher rates of non-reconstructable disease. This leads to higher rates of limb loss and interventions so this demographic has a high clinical utility. However, those with Buerger's disease tend to have fewer systemic comorbidities than people with atherosclerotic disease, making the findings of this review difficult to apply to other causes of PAD.

Management of people with $\mathrm{CLI}$ is advancing rapidly with a fewer number of people being treated as non-reconstructable. However, this advance in treatment options is not matched by an equivalent reduction in mortality or improvement in quality of life. These areas, as well as cost-effectiveness of the interventions, are not considered in the included trial. This trial was performed in participants with Buerger's disease diagnosed by Shionoyas criteria, which excludes participants with atherosclerotic or other aetiologies in whom the interventions of interest would play a significant role, limiting the applicability of the evidence. Another issue reducing applicability of the evidence from the single study, is the fact that the included trial did not use other methods of sympathectomy (e.g. CT-guided chemical sympathectomy or laparoscopic means), which arguably may yield better outcomes as they are less invasive and cause less disruption of the collateral vascular network. Also, there are inherent concerns with the assessment of ulcer healing. The included study did specify inclusion of those with ischaemic ulcers but they did not report their procedures for how they determined this. There is a risk the study included a mix of ulcers types (i.e. venous ulcers, neuropathic ulcers and ischaemic ulcers). Also, the methods of measuring ulcers can be quite variable, possibly biasing the results.

Treatment of PAD is rapidly changing and the definition of 'nonreconstructable PAD' shifts as new treatment becomes available and techniques are refined. As the single included study was reported over a decade ago, it is likely these participants would no longer fit the current definition of non-reconstructable PAD and also these treatment methods are not as commonly practiced. It should be noted that NICE guidelines currently only recommend lumbar sympathectomy in the context of a clinical trial as the outcomes for participants are unclear (NICE 2012).

\section{Quality of the evidence}

We included only a single trial in this review, which limits the quality of evidence. Parallel searches confirmed that we did not omit any published trials. The included trial was limited by its small size, lack of sample size calculation and participants missing from analysis due to insufficient data, thus the GRADE rating was low. A total of 200 participants were randomised, 100 in each study arm, but only $162(81 \%)$ were included in the analysis, and there was insufficient information provided on why the 38 participants were not included. Sixteen of the 100 randomised to the iloprost arm were not included and 22 of the 100 in the sympathectomy arm were not included. However, the estimates calculated from the trial are reasonable and the confidence intervals are not overly large. Larger studies with longer duration of follow-up, including other participant subgroups are necessary.

\section{Potential biases in the review process}

We made all attempts to limit potential bias in the review by having multiple authors select studies to be included, execute data extraction and rate the quality of the study. We could not identify any potential biases in the review process. However, it should be noted that the single study included in the review reported a single outcome of "complete healing without pain or major amputation" which we believe fits the criteria for three separate outcomes in our review: 'complete ulcer healing', 'avoidance of amputation' and 'pain relief'. After careful consideration we decided to report the findings as a single outcome, to accurately reflect the data presented in the original study publication. This required us to deviate from the protocol, but this was deemed superior to potentially misrepresenting the findings.

\section{Agreements and disagreements with other studies or reviews}

We were unable to identify any other systematic review or meta-analysis comparing the use of lumbar sympathectomy and prostanoids in non-reconstructable CLI.

Revascularisation remains the first line of intervention in people with CLI. Both lumbar sympathectomy and prostanoids have been identified to have positive results regarding rest pain relief, ulcer healing and amputations in people for whom revascularisation is not an appropriate treatment. As there is no conclusive evidence of the long-term effectiveness and safety, these treatment options are feasible only in people with non-reconstructable arterial disease who are at high risk of limb loss (Ruffolo 2010).

\section{AUTHORS' CONCLUSIONS}

\section{Implications for practice}

Data from a single trial provide low-quality evidence to suggest that prostaglandins are superior to open surgical lumbar sympathectomy in producing complete ulcer healing without rest pain or major amputation. This evidence was derived from a single study conducted using a select group of participants (with Buerger's disease). Prostaglandins appear to be well tolerated as compared to open surgical lumbar sympathectomy, although there were reports of mild adverse events. Costs and quality of life measures were not studied, therefore no clear indication can be given in these areas. However, these conclusions need verification in larger clinical trials, including participants with other methods of sympathectomy and other aetiologies of peripheral arterial disease (PAD). 


\section{Implications for research}

Further randomised trials are needed to more precisely define the relative and absolute benefits and risks of lumbar sympathectomy and prostaglandin infusion as treatment options in people with non-reconstructable PAD presenting with critical limb ischaemia (CLI). Studies analysing the costs, quality of life outcomes and longterm outcomes of these treatment modalities are required.

\section{ACKNOWLEDGEMENTS}

The protocol for this Cochrane Review is an output of a protocol development workshop conducted by the Prof. BV Moses and ICMR Centre for Advanced Research and Training in Evidence-Informed Healthcare (Sen 2011). 


\section{R E F E R E N C E S}

\section{References to studies included in this review}

Bozkurt 2006 \{published data only\}

Bozkurt AK, Koksal C, Demirbas MY, Erdogan A, Rahman A, Demirkilic $U$, et al. A randomised trial of intravenous Iloprost (a stable prostacyclin analogue) versus lumbar sympathectomy in the management of Buerger's disease. Final Programme and Book of Abstracts. 16th European Chapter Congress of the International Union of Angiology; 2005 Oct 25-27; Glasgow. 2005.

* Bozkurt AK, Koksal C, Demirbas MY, Erdogan A, Rahman A, Demirkilic U, et al. A randomized trial of intravenous iloprost (a stable prostacyclin analogue) versus lumbar sympathectomy in the management of Buerger's disease. International Angiology 2006;25(2):162-8. [PUBMED: 16763533]

\section{References to studies excluded from this review}

\section{Petronella 2004 \{published data only\}}

Petronella P, Freda F, Nunziata L, Antropoli M, Manganiello A, Cutolo PP, et al. Prostaglandin E1 versus lumbar sympathectomy in the treatment of peripheral arterial occlusive disease: randomised study of 86 patients. Nutrition, Metabolism, and Cardiovascular Diseases: NMCD 2004;14(4):186-92. [PUBMED: 15553595]

\section{Additional references}

\section{Abu Dabrh 2015}

Abu Dabrh AM, Steffen MW, Asi N, Undavalli C, Wang Z, Elamin MB, et al. Nonrevascularization-based treatments in patients with severe or critical limb ischemia. Journal of Vascular Surgery 2015;62(5):1330-9.

\section{Aquino 2001}

Aquino R, Johnnides C, Makaroun M, Whittle JC, Muluk VS, Kelley ME, et al. Natural history of claudication: long-term serial follow-up study of 1244 claudicants. Journal of Vascular Surgery 2001;34(6):962-70.

\section{Deeks 2011}

Deeks JJ, Higgins JP, Altman DG, editor(s). Chapter 9: Analysing data and undertaking meta-analyses. In: Higgins JP, Green S, editor(s). Cochrane Handbook for Systematic Reviews of Interventions Version 5.1.0 (updated March 2011). The Cochrane Collaboration, 2011. Available from www.handbook.cochrane.org.

\section{Diehm 2004}

Diehm C, Diehm N. Non-invasive treatment of critical limb ischemia. Current Drug Targets in Cardiovascular and Haematological Disorders 2004;4(3):241-7.

\section{Dormandy 1999}

Dormandy J, Heeck L, Vig S. The fate of patients with critical leg ischemia. Seminars in Vascular Surgery 1999;12(2):142-7.

\section{Egger 1997}

Egger M, Davey-Smith G, Schneider M, Minder C. Bias in meta-analysis detected by a simple graphical test. $B M J$ 1997;315(7109):629-34.

\section{Faglia 2009}

Faglia E, Clerici G, Clerissi J, Gabrielli L, Losa S, Mantero M, et al. Long-term prognosis of diabetic patients with critical limb ischemia: a population-based cohort study. Diabetes Care 2009;32(5):822-7.

\section{Fontaine 1954}

Fontaine VR, Kim M, Kieny R. Surgical treatment for peripheral circulation disorders [Die chirurgische Behandlungder peripheren Durchblutungsstorungen]. Helvetica Chirurgica Acta 1954;21(5-6):499-533.

\section{Fowkes 2013}

Fowkes RG, Rudan D, Rudan I, Aboyans V, Denenberg JO, McDermott MM. Comparison of global estimates of prevalence and risk factors for peripheral artery disease in 2000 and 2010: a systematic review and analysis. Lancet 2013;382(9901):1329-40.

\section{GRADEpro GDT 2015 [Computer program]}

McMaster University (developed by Evidence Prime). GRADEpro GDT. Version accessed 9 October 2017. Hamilton (ON): McMaster University (developed by Evidence Prime), 2015.

\section{Higgins 2002}

Higgins JP, Thompson SG. Quantifying heterogeneity in a metaanalysis. Statistics in Medicine 2002;21(11):1539-58.

\section{Higgins 2011}

Higgins JP, Green S, editor(s). Cochrane Handbook for Systematic Reviews of Interventions Version 5.1.0 (updated March 2011). The Cochrane Collaboration, 2011. Available from www.handbook.cochrane.org.

\section{Hirsh 2001}

Hirsch AT, Criqui MH, Treat-Jacobson D, Regensteiner JG, Creager MA, Olin JW, et al. Periperal arterial disease detection, awareness, and treatment in primary care. JAMA 2001;286(11):1317-24.

\section{Karanth 2016}

Karanth VKL, Karanth TK, Karanth L. Lumbar sympathectomy techniques for critical lower limb ischaemia due to nonreconstructable peripheral arterial disease. Cochrane Database of Systematic Reviews 2016, Issue 12. [DOI: 10.1002/14651858.CD011519.pub2]

\section{Kullo 2016}

Kullo IJ, Rooke TW. Peripheral artery disease. New England Journal of Medicine 2016;374(9):861-71.

\section{Lee 2006}

Lee AD, Agarwal S, Sadhu D. A 7-year experience with thoracoscopic sympathectomy for critical upper limb ischemia. World Journal of Surgery 2006;30(9):1644-7. 


\section{Liberati 2009}

Liberati A, Altman DG, Tetzlaff J, Mulrow C, Gotzsche PC, loannidis JP, et al. The PRISMA statement for reporting systematic reviews and meta-analyses of studies that evaluate health care interventions: explanation and elaboration. PLOS Medicine 2009;6(7):e1000100.

\section{McDermott 2001}

McDermott MM, Greenland P, Liu K. Leg symptoms in peripheral arterial disease. JAMA 2001;286(13):1599-1606.

\section{NICE 2012}

National Institute for Health and Care Excellence. Peripheral arterial disease: diagnosis and management (CG147). www.nice.org.uk/guidance/cg1479 (accessed 4 August 2017).

\section{Norgren 2007}

Norgren L, Hiatt WR, Dormandy JA, Nehler MR, Harris KA, Fowkes FG, et al. Inter-society consensus for the management of peripheral arterial disease (TASC II). European Journal of Vascular and Endovascular Surgery 2007;33(Suppl 1):S1-S75.

\section{Pieri 2005}

Pieri S, Agresti P, lalongo P, Fedeli S, Di Cesare F, Ricci G. Lumbar sympathectomy under CT guidance: therapeutic option in critical limb ischaemia. Radiology in Medicine 2005;109(4):430-7.

\section{Review Manager 2014 [Computer program]}

Nordic Cochrane Centre, The Cochrane Collaboration. Review Manager 5 (RevMan 5). Version 5.3. Copenhagen: Nordic Cochrane Centre, The Cochrane Collaboration, 2014.

\section{Robertson 2013}

Robertson L, Andras A. Prostanoids for intermittent claudication. Cochrane Database of Systematic Reviews 2013, Issue 4. [DOI: 10.1002/14651858.CD000986.pub3]

\section{Rowe 2009}

Rowe V, Lee W, Weaver FA, Etzioni D. Patterns of treatment for peripheral arterial disease in the United States: 1996-2005. Journal of Vascular Surgery 2009;49(4):910-7.

\section{Ruffolo 2010}

Ruffolo AJ, Romano M, Ciapponi A. Prostanoids for critical limb ischaemia. Cochrane Database of Systematic Reviews 2010, Issue 1. [DOI: 10.1002/14651858.CD006544.pub2]

\section{Schünemann 2011}

Schünemann HJ, Oxman AD, Vist GE, Higgins JP, Deeks JJ, Glasziou P, et al. Chapter 12: Interpreting results and drawing conclusions. In: Higgins JP, Green S, editor(s). Cochrane Handbook for Systematic Reviews of Interventions. Version 5.1.0 (updated March 2011). The Cochrane Collaboration, 2011. Available from www.handbook.cochrane.org.

\section{Steg 2007}

Steg G, Bhatt DL, Wilson WF. One-year cardiovascular event rates in outpatients with atherothrombosis. JAMA 2007;297(11):1197-206.

\section{Tay 2002}

Tay VK, Fitridge R, Tie MLH. Computed tomography fluoroscopyguided chemical lumbar sympathectomy: simple, safe and effective. Journal of Medical Imaging and Radiation Oncology 2002;46(2):163-6.

\section{References to other published versions of this review Sen 2011}

Sen I, Agarwal S, Tharyan P. Lumbar sympathectomy versus prostanoids for critical limb ischaemia due to nonreconstructable peripheral arterial disease. Cochrane Database of Systematic Reviews 2011, Issue 10. [DOI: 10.1002/14651858.CD009366]

* Indicates the major publication for the study

\section{CHARACTERISTICS OF STUDIES}

Characteristics of included studies [ordered by study ID]

Bozkurt 2006

Design: randomised parallel-group multicentre controlled clinical trial
Setting : 12 major vascular centres
Country: Turkey
Loss to follow-up: complete data from 162 participants presented in the analysis after a follow-up of 4
and 24 weeks (19\% of participants missing from analysis; $16 \%$ in iloprost group and $22 \%$ in sympathec-
tomy group)
Intention-to-treat: not stated

Participants Number randomised $\mathrm{n}=200$ (iloprost $\mathrm{n}=100$; sympathectomy $\mathrm{n}=100$ ); number analysed at 24 weeks (iloprost $n=84$; sympathectomy $n=78$ ) 
Bozkurt 2006 (Continued)

Average age (range): 40.8 years ( 25 to 66 )

Gender: male: $97.6 \%$

No systemic comorbidities

Inclusion criteria:

- Buerger's disease diagnosed by Shionoyas criteria

- Critical ischaemia - rest pain/ischaemic ulcer

Exclusion criteria: not mentioned

Interventions

Prostanoid iloprost; intravenous infusion $1 \mathrm{ng} / \mathrm{kg} / \mathrm{min}$, six hours/day for 28 days

Open surgical unilateral sympathectomy at lumbar levels 2, 3, 4

Reported in paper, used in review
- relief of rest pain
- ulcer healing
- avoidance of major amputation
- mortality
Reported, not used
- change in ulcer size
- $50 \%$ reduction in ulcer size
- analgesic requirements
- clinical improvement by SVS/ISCVS
Sought from authors: not reported
- claudication distances
- ABPI, tissue oxygenation (TCPO 2 ), toe pressure
- progression to minor amputation
- quality of life and functional status
- analysis of cost-effectiveness
Duration of follow-up: 24 weeks

Notes Funding: research fund of Istanbul University

Comments: no conflicts of interest

Trial was not registered

\section{Risk of bias}

\begin{tabular}{lll}
\hline Bias & Authors' judgement & Support for judgement \\
\hline $\begin{array}{l}\text { Random sequence genera- } \\
\text { tion (selection bias) }\end{array}$ & Low risk & $\begin{array}{l}\text { Quote from report: "independent statistician prepared the randomisation list } \\
\text { by the method of computer generated random numbers." }\end{array}$ \\
\hline $\begin{array}{l}\text { Allocation concealment } \\
\text { (selection bias) }\end{array}$ & Low risk & Use of randomly generated list prepared by an independent statistician \\
\hline $\begin{array}{l}\text { Blinding (performance } \\
\text { bias and detection bias) }\end{array}$ & Unclear risk & $\begin{array}{l}\text { Blinding of participants was not possible due to the nature of intervention - a } \\
\text { drug was being compared to a surgical procedure }\end{array}$ \\
\hline
\end{tabular}


Bozkurt 2006 (Continued)

Subjective outcome (pain)
Pain is a subjective outcome and no data on objective recordings, e.g. using pain scores is reported; it was not reported if a blinded assessor or adjudication committee was used

\begin{tabular}{|c|c|c|}
\hline $\begin{array}{l}\text { Blinding (performance } \\
\text { bias and detection bias) } \\
\text { Objective outcomes (am- } \\
\text { putation, healing) }\end{array}$ & Low risk & $\begin{array}{l}\text { Amputation and ulcer healing are definite clinical outcomes, evidence of risk } \\
\text { of bias for these outcomes is minimal. } \\
\text { Data on objective documentation of ulcer healing are presented, which also } \\
\text { reduces the risk of bias }\end{array}$ \\
\hline $\begin{array}{l}\text { Incomplete outcome data } \\
\text { (attrition bias) } \\
\text { All outcomes }\end{array}$ & Unclear risk & $\begin{array}{l}162 \text { of } 200 \text { randomised participants included in analysis; both groups had simi- } \\
\text { lar numbers of dropouts: iloprost } n=16 \text {, sympathectomy } n=22 \text {; study quoted } \\
\text { missing participant data as "insufficient data for the remaining participants" } \\
\text { with no further information on reasons so we judged attrition bias as unclear }\end{array}$ \\
\hline $\begin{array}{l}\text { Selective reporting (re- } \\
\text { porting bias) }\end{array}$ & Low risk & $\begin{array}{l}\text { Although the trial was not registered, all proposed outcome measures were re- } \\
\text { ported adequately }\end{array}$ \\
\hline Other bias & Low risk & None detected by the review authors \\
\hline
\end{tabular}

ABPI: ankle brachial pressure index

SVS/ISCVS: Society for Vascular Surgery and the North American Chapter of the International Society for Cardiovascular Surgery

\section{Characteristics of excluded studies [ordered by year of study]}

\begin{tabular}{|c|c|}
\hline Study & Reason for exclusion \\
\hline Petronella 2004 & $\begin{array}{l}\text { The study did not match our inclusion criteria as it included some participants requiring surgi- } \\
\text { cal revascularisation. This is likely to influence the outcome of the intervention under study. Sur- } \\
\text { gical revascularisation is the first line of management for critical ischaemia, without which relief } \\
\text { of ischaemic pain is low and rates of limb loss are high. Treating such a participant group with } \\
\text { prostaglandin or sympathectomy may cause a delay in revascularisation and theoretically wors- } \\
\text { en the stage of ischaemia. Performance of revascularisation after the trial intervention also influ- } \\
\text { ences the outcome follow-up: participants with successful revascularisation will report better out- } \\
\text { comes, which would then make it unclear if this improvement is because of the study intervention } \\
\text { or the revascularisation. The study also included a few participants with early stages of disease, } \\
\text { again prostaglandin or sympathectomy are not acceptable treatment modalities in such people. Al- } \\
\text { so, the method of randomisation and participant assignment was unclear. }\end{array}$ \\
\hline
\end{tabular}

\section{DATA AND ANALYSES}

\section{Comparison 1. Prostanoids versus lumbar sympathectomy}

\begin{tabular}{lllll}
\hline Outcome or subgroup title & No. of studies & $\begin{array}{l}\text { No. of partici- } \\
\text { pants }\end{array}$ & Statistical method & Effect size \\
\hline $\begin{array}{l}1 \text { Complete ulcer healing without rest pain } \\
\text { or major amputation at 24 weeks (per proto- } \\
\text { col analysis) }\end{array}$ & 1 & Risk Ratio (M-H, Fixed, & $\begin{array}{l}\text { Totals not select- } \\
\text { ed }\end{array}$ & \\
\hline
\end{tabular}




\begin{tabular}{|c|c|c|c|c|}
\hline Outcome or subgroup title & No. of studies & $\begin{array}{l}\text { No. of partici- } \\
\text { pants }\end{array}$ & Statistical method & Effect size \\
\hline $\begin{array}{l}2 \text { Complete ulcer healing without rest pain } \\
\text { or major amputation at } 24 \text { weeks (ITT/sensi- } \\
\text { tivity analysis) }\end{array}$ & 1 & & $\begin{array}{l}\text { Risk Ratio (M-H, Fixed, } \\
95 \% \mathrm{Cl})\end{array}$ & $\begin{array}{l}\text { Totals not select- } \\
\text { ed }\end{array}$ \\
\hline 3 Mortality (per protocol analysis) & 1 & & $\begin{array}{l}\text { Risk Ratio (M-H, Fixed, } \\
95 \% \mathrm{Cl})\end{array}$ & $\begin{array}{l}\text { Totals not select- } \\
\text { ed }\end{array}$ \\
\hline 4 Mortality (ITT/sensitivity analysis) & 1 & & $\begin{array}{l}\text { Risk Ratio (M-H, Fixed, } \\
95 \% \mathrm{Cl})\end{array}$ & $\begin{array}{l}\text { Totals not select- } \\
\text { ed }\end{array}$ \\
\hline
\end{tabular}

Analysis 1.1. Comparison 1 Prostanoids versus lumbar sympathectomy, Outcome 1 Complete ulcer healing without rest pain or major amputation at 24 weeks (per protocol analysis).

\begin{tabular}{|c|c|c|c|c|c|c|c|}
\hline \multirow{2}{*}{$\begin{array}{l}\text { Study or subgroup } \\
\text { Bozkurt } 2006\end{array}$} & $\begin{array}{c}\text { Prostanoids } \\
\mathrm{n} / \mathrm{N}\end{array}$ & $\begin{array}{c}\text { Sympathectomy } \\
\mathrm{n} / \mathrm{N} \\
\end{array}$ & \multicolumn{3}{|c|}{$\begin{array}{c}\text { Risk Ratio } \\
\text { M-H, Fixed, 95\% Cl }\end{array}$} & & \multirow{2}{*}{$\begin{array}{c}\begin{array}{c}\text { Risk Ratio } \\
\text { M-H, Fixed, 95\% Cl }\end{array} \\
1.63[1.3,2.05\end{array}$} \\
\hline & $72 / 84$ & $41 / 78$ & & & + & & \\
\hline
\end{tabular}

Analysis 1.2. Comparison 1 Prostanoids versus lumbar sympathectomy, Outcome 2 Complete ulcer healing without rest pain or major amputation at 24 weeks (ITT/sensitivity analysis).

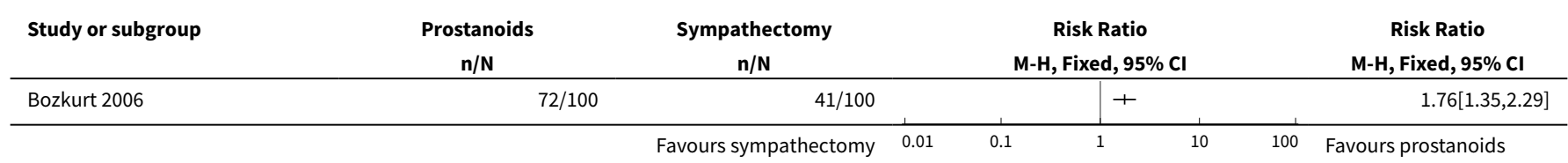

Analysis 1.3. Comparison 1 Prostanoids versus lumbar sympathectomy, Outcome 3 Mortality (per protocol analysis).

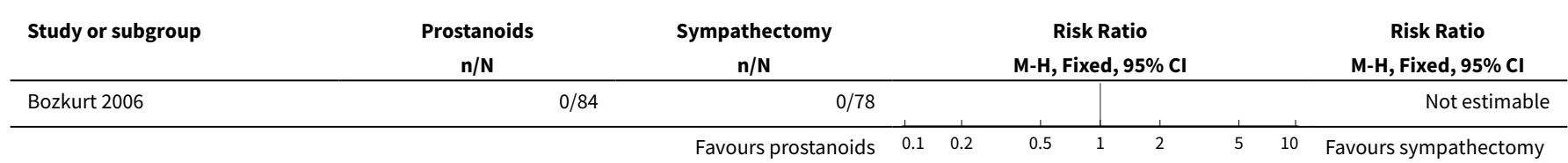

Analysis 1.4. Comparison 1 Prostanoids versus lumbar sympathectomy, Outcome 4 Mortality (ITT/sensitivity analysis).

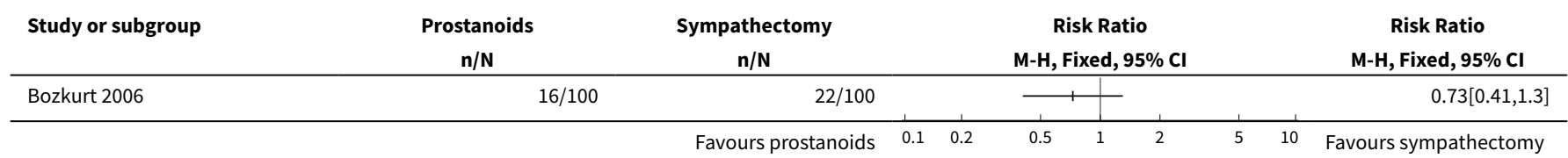




\title{
APPENDICES
}

\section{Appendix 1. CENTRAL search strategy}

\author{
Search run on Wed Mar 292017
}

\begin{tabular}{|c|c|c|}
\hline \#1 & MESH DESCRIPTOR Arteriosclerosis & 869 \\
\hline \#2 & MESH DESCRIPTOR Arteriolosclerosis EXPLODE ALL TREES & 0 \\
\hline \#3 & MESH DESCRIPTOR Arteriosclerosis Obliterans & 72 \\
\hline \#4 & MESH DESCRIPTOR Atherosclerosis & 645 \\
\hline \#5 & MESH DESCRIPTOR Arterial Occlusive Diseases & 737 \\
\hline \#6 & MESH DESCRIPTOR Intermittent Claudication & 726 \\
\hline$\# 7$ & MESH DESCRIPTOR Ischemia & 803 \\
\hline \#8 & MESH DESCRIPTOR Peripheral Vascular Diseases EXPLODE ALL TREES & 2236 \\
\hline \#9 & (atherosclero* or arteriosclero* or PVD or PAOD or PAD ):TI,AB,KY & 9509 \\
\hline \#10 & 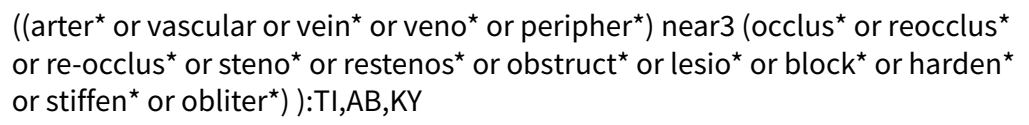 & 8385 \\
\hline \#11 & (peripheral near3 dis ${ }^{\star}$ ):TI,AB,KY & 3533 \\
\hline \#12 & (claudic* or IC):TI,AB,KY & 3229 \\
\hline \#13 & (isch* or CLI):TI,AB,KY & 24788 \\
\hline \#14 & arteriopathic or leriche ${ }^{\star}: \mathrm{TI}, \mathrm{AB}, \mathrm{KY}$ & 65 \\
\hline \#15 & dysvascular ${ }^{\star}: \mathrm{TI}, \mathrm{AB}, \mathrm{KY}$ & 11 \\
\hline \#16 & $\begin{array}{l}\text { (leg near3 } \text { occlus }^{\star} \text { or reocclus }{ }^{\star} \text { or re-occlus }{ }^{\star} \text { or steno* } \text { or restenos }^{\star} \text { or ob- } \\
\left.\text { struct }^{\star} \text { or lesio } \text { or block }^{\star} \text { or harden } \text { or stiffen }^{\star} \text { or obliter }{ }^{\star}\right) \text { ):TI,AB,KY }\end{array}$ & 99 \\
\hline \#17 & $\begin{array}{l}\text { (limb near3 }\left(\text { occlus }^{\star} \text { or reocclus }{ }^{\star} \text { or re-occlus }{ }^{\star} \text { or steno* or restenos* or ob- }\right. \\
\left.\text { struct }^{\star} \text { or lesio* or block } \text { or harden }^{\star} \text { or stiffen* or obliter }{ }^{\star}\right) \text { ):TI,AB,KY }\end{array}$ & 158 \\
\hline \#18 & 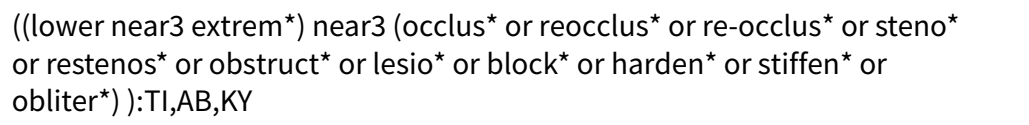 & 82 \\
\hline \#19 & MESH DESCRIPTOR Leg EXPLODE ALL TREES WITH QUALIFIERS BS & 1113 \\
\hline \#20 & MESH DESCRIPTOR Iliac Artery & 147 \\
\hline
\end{tabular}


(Continued)

\begin{tabular}{|c|c|c|}
\hline \#21 & MESH DESCRIPTOR Popliteal Artery & 282 \\
\hline$\# 22$ & MESH DESCRIPTOR Femoral Artery & 834 \\
\hline \#23 & MESH DESCRIPTOR Tibial Arteries & 33 \\
\hline$\# 24$ & 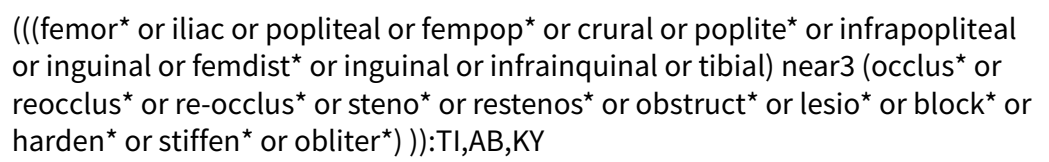 & 1220 \\
\hline$\# 25$ & $\begin{array}{l}\# 1 \text { OR \#2 OR \#3 OR \#4 OR \#5 OR \#6 OR \#7 OR \#8 OR \#9 OR \#10 OR \#11 OR \#12 } \\
\text { OR \#13 OR \#14 OR \#15 OR \#16 OR \#17 OR \#18 OR \#19 OR \#20 OR \#21 OR \#22 OR } \\
\text { \#23 or \#24 }\end{array}$ & 45798 \\
\hline \#26 & MESH DESCRIPTOR Sympathectomy EXPLODE ALL TREES & 136 \\
\hline$\# 27$ & sympathectom: $\mathrm{TI}, \mathrm{AB}, \mathrm{KY}$ & 231 \\
\hline$\# 28$ & MESH DESCRIPTOR Lumbosacral Plexus EXPLODE ALL TREES & 877 \\
\hline$\# 29$ & (lumbosacral plexus): $\mathrm{Tl}, \mathrm{AB}, \mathrm{KY}$ & 140 \\
\hline \#30 & \#26 OR \#27 OR \#28 OR \#29 & 1125 \\
\hline \#31 & MESH DESCRIPTOR Prostaglandins EXPLODE ALL TREES & 4794 \\
\hline$\# 32$ & MESH DESCRIPTOR Thromboxanes EXPLODE ALL TREES & 744 \\
\hline \#33 & *prosta*:TI,AB,KY & 19951 \\
\hline \#34 & $P G E^{\star}: T I, A B, K Y$ & 1846 \\
\hline$\# 35$ & $P G I^{\star}: T I, A B, K Y$ & 765 \\
\hline \#36 & (AS-013 or ventavis or TTC-909) ):TI,AB,KY & 8 \\
\hline \#37 & thrombox ${ }^{*}: \mathrm{TI}, \mathrm{AB}, \mathrm{KY}$ & 1528 \\
\hline \#38 & \#31 OR \#32 OR \#33 OR \#34 OR \#35 OR \#36 OR \#37 & 22496 \\
\hline \#39 & \#25 AND \#30 AND \#38 & 6 \\
\hline
\end{tabular}

\section{Appendix 2. Trials registries searches}

CT.gov

1 study found for: lumbar sympathectomy

WHO

No results were found for: lumbar sympathectomy

ISRCTN

No results were found for: lumbar sympathectomy 


\section{CONTRIBUTIONSOF AUTHORS}

IS: wrote protocol; trial selection, assessed quality, extracted data, performed meta-analyses, interpreted results, and wrote the review manuscript.

SA: helped in writing the protocol; extracted data, interpreted results, and wrote the review manuscript.

PT: helped in writing the protocol; assessed quality, extracted data, performed meta-analysis, and wrote the review manuscript.

RF: assisted in writing the review manuscript and performing the meta-analysis.

\section{DECLARATIONS OF INTEREST}

IS: none known.

SA: none known.

PT: PT's institution has received funding from the Indian Council for Medical Research (ICMR): the Professor BV Moses Centre was funded by an educational grant from the Indian Council for Medical Research during the development of the protocol for this Cochrane Review. RF: none known.

\section{SOURCES OF SUPPORT}

\section{Internal sources}

- Christian Medical College, Vellore, India.

Salaries and infrastructure support for all authors

- Prof. BV Moses \& Indian Council of Medical Research (ICMR) Centre for Advanced Research in Evidence-Informed Healthcare, India.

Technical support for protocol development and review completion

\section{External sources}

- Indian Council of Medical Research (ICMR), India.

Funding for the Prof. BV Moses Centre for Evidence-Informed Healthcare

- Chief Scientist Office, Scottish Government Health Directorates, The Scottish Government, UK.

The Cochrane Vascular editorial base is supported by the Chief Scientist Office.

\section{DIFFERENCES BETWEEN PROTOCOLANDREVIEW}

The outcome referring to walking distances has been modified to 'intermittent and absolute claudication distance (pain-free walking distance and maximum walking distance, respectively)'. The two separate walking distances were clarified and 'increase in' was removed as we want to report any change in walking distances and not only if there is an increase.

The outcome of ankle brachial pressure index (ABPI) was edited to only 'ABPI' and 'improvement of' was removed as we intend to report on any ABPI findings and not only those that show improvement.

The protocol stated that an intention-to-treat (ITT) analysis would be performed as the primary analysis, where possible. After inclusion of only a single study with a high rate of unexplained dropouts, we chose to report a per protocol analysis as the primary analysis and include the ITT population in a sensitivity analysis.

We combined three individual primary outcomes of 'relief of rest pain', 'ulcer healing' and 'avoidance of major amputation' into a single outcome to reflect the outcome reported in the only included study, 'complete healing of ulcer without rest pain or major amputation'. We chose to do this after careful consideration in order to reduce a possible bias when interpreting the individual outcomes.

\section{NDEX TERMS}

\section{Medical Subject Headings (MeSH)}

Iloprost [*therapeutic use]; Ischemia [*drug therapy] [etiology] [*surgery]; Leg Ulcer [drug therapy] [etiology] [surgery]; Pain Management [ ${ }^{\star}$ methods]; Peripheral Arterial Disease [ ${ }^{\star}$ complications]; Prostaglandins [therapeutic use]; Sympathectomy [ ${ }^{*}$ methods]; Thromboangiitis Obliterans [ ${ }^{*}$ complications]; Vasodilator Agents [ ${ }^{\star}$ therapeutic use]

\section{MeSH check words}

Humans 